Research paper

\title{
Public attitudes toward depression and help-seeking: Impact of the OSPI- Europe depression awareness campaign in four European regions
}

\author{
Elisabeth Kohls ${ }^{\mathrm{a}, \mathrm{d}, *}$, Evelien Coppens ${ }^{\mathrm{b}}$, Juliane Hug ${ }^{\mathrm{c}, \mathrm{d}}$, Eline Wittevrongel ${ }^{\mathrm{b}}$, \\ Chantal Van Audenhove ${ }^{\mathrm{b}}$, Nicole Koburger ${ }^{\mathrm{c}}$, Ella Arensman ${ }^{\mathrm{e}}$, András Székely ${ }^{\mathrm{f}}$, Ricardo Gusmão ${ }^{g}$, \\ Ulrich Hegerl ${ }^{\mathrm{a}, \mathrm{c}, \mathrm{d}}$
}

a Department of Psychiatry and Psychotherapy, Medical Faculty, University Leipzig, Leipzig, Germany

b LUCAS Center for Care Research and Consultancy, KU Leuven, Leuven, Belgium

${ }^{\mathrm{c}}$ Depression Research Centre, German Depression Foundation, Leipzig, Germany

d European Alliance Against Depression (EAAD), Leipzig, Germany

e National Suicide Research Foundation and Department of Epidemiology and Public Health, University College Cork, Ireland

${ }^{\mathrm{f}}$ Institute of Behavioural Sciences, Semmelweis University, Budapest, Hungary

${ }^{g}$ Instituto de Saúde Pública, Universidade do Porto (ISPUP), Porto, Portugal

\section{A R T I C L E I N F O}

\section{Keywords:}

Depression

Public attitudes

Help-seeking

Stigma

\begin{abstract}
A B S T R A C T
Background: Public attitudes toward depression and help-seeking behaviour are important factors influencing depressed people to obtain professional help and adequate treatment. OSPI-Europe is a multi-level suicide prevention programme including a public awareness campaign. It was implemented in four regions of four European countries (Germany, Hungary, Ireland and Portugal). This paper reports the results of the evaluation of the campaign, including its visibility and effects of the campaign on stigma associated with depression and helpseeking behaviour.

Methods: A representative general population survey $(\mathrm{N}=4004)$ including measures on personal stigma, perceived stigma, openness to help, perceived value of help, and socio-demographic variables was conducted in the four intervention and four control regions in a cross-sectional pre-post design.

Results: The public awareness campaign was considerably more visible in Germany and Portugal compared to Ireland and Hungary. Visibility was further affected by age and years of schooling. Personal stigma, perceived stigma and openness toward professional help varied significantly across the four countries. Respondents in the intervention regions showed significantly less personal depression stigma than respondents in the control regions after the campaign. Respondents of the intervention region who were aware of the campaign reported more openness toward seeking professional help than respondents who were unaware of it.

Conclusion: The OSPI-Europe awareness campaign was visible and produced some positive results. At the same time, it proved to be difficult to show strong, measurable and unambiguous effects, which is in line with previous studies. Public awareness campaigns as conducted within OSPI-Europe can contribute to improved attitudes and knowledge about depression in the general public and produce synergistic effects, in particular when the dissemination of awareness campaign materials is simultaneously reinforced by other intervention levels of a multi-level intervention programme.
\end{abstract}

Limitations: The survey was cross-sectional and based on self-report, so no causal inferences could be drawn.

\section{Introduction}

According to the World Health Organization (WHO), depression is the most prominent single cause of disability worldwide, accounting for $11 \%$ of all years lived with disability globally. Depression has high life time prevalence within the international range of $6.3-10.3 \%$, a large comorbidity (Baumeister and Härter, 2007), mortality (Ustün et al.,
2004; Thomson, 2011) and a considerable economic impact (Chisholm et al., 2016). Although adequate treatment is available (Anderson, 2000; DeRubeis et al., 2005; Cipriani et al., 2009; NICE, 2009), it is estimated that $56 \%$ of patients with major depression receive no treatment at all (Kohn et al., 2004; Fernández et al., 2007) Previous research has identified several factors contributing to this, including barriers to care or reach out for help. Stigmatization and fear of

\footnotetext{
* Corresponding author at: Department of Psychiatry and Psychotherapy, Medical Faculty, University Leipzig, Semmelweisstraße 10, Haus 13, 04103 Leipzig, Germany.

E-mail address: Elisabeth.Kohls@medizin.uni-leipzig.de (E. Kohls).
} 
discrimination are amongst others seen as major barriers to perform help-seeking behaviour (Clement et al., 2015). There is evidence, that public stigma, which represents such opinions about personal beliefs of what most people think, is positively associated with self-stigma (Evans-Lacko et al., 2012) and negatively associated with help-seeking for mental health related problems (Griffiths et al., 2011; Clement et al., 2015).

Studies indicate that approximately half of the general public is convinced that people with depression are weak, responsible for their own condition and unpredictable; and nearly a quarter considers them to be dangerous (Wang and Lai, 2008; Aromaa et al., 2011).

The literature suggests that it is important to make a distinction between personal and perceived depression stigma (Griffiths et al., 2008; Eisenberg et al., 2009; Calear et al., 2011). Personal stigma is referred to as an individual's personal thoughts and beliefs about depression, while perceived depression stigma represents an individual's perception of what other people think and feel about depression (Griffiths et al., 2006; Calear et al., 2011). It is generally assumed that both stigmatizing concepts negatively affect an individual's decision to seek help for a mental health problem (Barney et al., 2006; Griffiths et al., 2008).

The baseline data from the first wave survey of OSPI-Europe showed a moderate degree of personal stigma toward depression and a strikingly higher degree of perceived stigma (Coppens et al., 2013). A significant association was found between personal stigma and attitudes toward help-seeking. Furthermore, personal stigma was related to less openness to search for help and lower perceived value of treatment. Socio-demographic characteristics such as male gender, older age and lower educational level were associated with more personal stigma and more negative attitudes toward help seeking. Finally, some significant country differences were found. Hungarian people showed the highest personal stigma, were least willing to look for professional help and were most likely to judge professional help as useless. Irish people, on the contrary, had the most positive attitudes toward depression and most frequently judged professional help to be valuable. Ultimately, German people scored the highest on perceived stigma and Portuguese people were most willing to seek professional help.

Numerous institutions, including the WHO, recommend education and public awareness campaigns aiming to counteract the stigma associated with mental illness, to prevent discrimination of people affected, to improve the mental health literacy of the public and to positively influence help-seeking behaviour (Dumesnil and Verger, 2009). Examples for such campaigns are: the Defeat Depression and the Changing Minds campaigns in the United Kingdom (Paykel et al., 1997; Crisp et al., 2005), the Community Awareness, the beyondblue and the Compass campaigns in Australia (Rosen et al., 2000; Jorm et al., 2005; Wright et al., 2006), the Like Minds, Like Mine campaign in New Zealand (Akroyd and Wyllie, 2003), the See Me campaign in Scotland (Braunholtz et al., 2004), as well as the Nuremberg Alliance Against Depression (Hegerl et al., 2003; Dietrich et al., 2010, 2014) and the recent Psychenet campaign in Germany (Makowski et al., 2016b). Most of these campaigns are rather expensive. Consequently, it is worthwhile to know whether they are effective, in particular in terms of behaviour change. Despite some evidence, the majority of campaigns resulted in only moderate improvements in knowledge of and attitudes toward depression and suicide (Dumesnil and Verger, 2009; Makowski et al., 2016b). While Jorm and colleagues found a positive impact on attitudes toward help seeking and treatment for the beyondblue campaign (Australia) (Jorm et al., 2005), in the majority of studies, the campaign did not produce a change in the tendency to seek professional help. Moreover, there are various methodological restrictions (Dumesnil and Verger, 2009): First, most studies, by using a repeated cross-sectional pre-post design without control groups, provided only a low level of evidence on effectiveness. The few existing studies that did include an unexposed control group were biased by several factors such as a nonrandomized sample selection, low response rates or small sample sizes. Second, most of the indicators and instruments used to measure the effect of a campaign on the population's knowledge and attitudes were not standardized, unreliable or invalidated (Dumesnil and Verger, 2009; Clement et al., 2015).

Although previous studies report heterogeneous and rather small effects and the evaluation of complex public campaigns is methodologically challenging, it is common practice and recommended standard in suicide prevention programmes to evaluate any intervention activities (World Health Organization (WHO), 2012, 2014). This paper focuses on a campaign evaluation study using a representative general population survey in four European countries in a pre-post design, which intended to not only follow this recommendation, but to address some of the limitations mentioned above. It forms part of the "Optimizing Suicide Prevention Programmes and their Implementation in Europe" project (OSPI-Europe,(Hegerl et al., 2009)). This large-scale project was funded by the European Commission within the seventh framework programme and ran from 2008 until 2013. It aimed at investigating the effectiveness of a multi-level community based suicide prevention programme in four culturally different European regions (in Germany, Hungary, Ireland, and Portugal), based on an optimised version of a 4-level community-based intervention concept implemented and evaluated in previous projects. One of the levels aimed to increase the population's knowledge about depression and its treatment as well as to decrease stigmatizing attitudes by means of a public media campaign. The other levels include: training primary care physicians, training community facilitators, supporting patients and their relatives, and restricting access to lethal means. The current study reports on the changes in depression stigma and attitudes towards help-seeking provoked by the public media campaign which was launched in four European countries. The aim of the study is threefold:

1) To examine whether the campaign activities were more visible in the intervention regions compared to the control regions in each of the four European countries

2) To determine the effect of the campaign activities on personal and perceived stigma toward depression and attitudes toward seeking professional help, and

3) To investigate whether effects differed between the respondents of the intervention regions who were aware of the campaign versus all subjects of the control regions who were not exposed to the campaign.

Additionally, a potential association of the results with certain socio-demographic characteristics was analysed.

\section{Method}

\subsection{The OSPI-Europe Awareness campaign}

Within the context of the OSPI-Europe intervention, a public depression awareness campaign was launched focusing on four key messages: "Depression is a real disease", "Depression can affect anyone", "Depression has many faces", and "Depression can be treated". The core campaign consisted of several activities, including: an opening ceremony, public informational events, the distribution of posters and flyers, and an intensified cooperation with the local press. The intensity of the campaign differed across regions. Table 1 provides an overview of the number of distributed flyers, put up posters, and organised public events per region. Several regions added optional activities to the core campaign such as brochures on depression distributed by general practitioners (GPs) and during public events (Leipzig), a movie spot on depression shown at a local cinema (Leipzig, Miskolc), a radio spot broadcasted several times a day (Miskolc), information on depression broadcasted via the teletext service of the local television (Miskolc), and key rings with an imprinted helpline number and slogan (e.g., "depression can be treated") distributed by GPs and local youth 
Table 1

Overview of OSPI-Europe intervention measures of the public depression awareness campaign.

\begin{tabular}{llllll}
\hline & Germany & Hungary & Ireland & Portugal & Total \\
\hline Flyers & 175200 & 60000 & 40000 & 130000 & $\mathbf{4 0 5 2 0 0}$ \\
Posters & 2748 & 3303 & 10025 & 5045 & $\mathbf{2 1 1 2 1}$ \\
Public events & 45 & 9 & 1 & 8 & 63 \\
\hline
\end{tabular}

agencies (Limerick). Finally, during all activities and on all printed materials across regions reference was made to a shared logo.

\subsection{Design and procedure}

In each OSPI-Europe country (Germany, Hungary, Ireland and Portugal), four intervention regions were selected in which the above described awareness campaign was implemented for at least 18 months. In addition, a control region was selected in each country which was comparable to the intervention region in terms of urbanity and which was not exposed to the campaign. A representative general population survey by means of telephone interviews was conducted in a controlled pre-post design in these intervention and control regions. The survey was carried out in each region shortly before intervention onset (wave 1) and repeated circa 21 months later (wave 2). Importantly, different samples of respondents were queried during the two data collection moments to eliminate confounding effects caused by a confirmation bias. Please see Table 2 and Fig. 1 for more details on the study design. A European market research firm with a track record in conducting surveys related to mental health was commissioned, including native language interviewers, to perform the telephone interviews. All interviewers received training, which included how to introduce the OSPIEurope programme, ethical issues and personal safety. For further details, see (Coppens et al., 2013).

\subsection{Survey instrument}

At wave 1 and 2, the same survey was carried out in the four intervention and the four control regions. The survey collected information on socio-demographic information (including gender, age, years of schooling, marital status and occupational status) and assessed whether a close family member or friend had ever (1) suffered from a depressive disorder, (2) deliberately self-harmed him or herself, or (3) died by suicide. Moreover, the Depression Stigma Scale (DSS;(Griffiths et al., 2004) was used to assess participants' attitudes towards depression. The DSS consists of two subscales - the Personal Stigma subscale and the Perceived Stigma subscale - each of them comprising of 9 items. Participants respond on each item via a five-point Likert scale ranging from "strongly disagree" (score 1) to "strongly agree" (score 5). Scale scores are calculated by summing scale items, with higher scores indicating more stigmatizing attitudes. Public attitudes towards helpseeking were assessed via the Attitude towards Seeking Professional Psychological Help Short Form (ATSPPH-SF) (Fisher \& Farina, 1995). The questionnaire consists of two subscales each consisting of five items: the Openness to Seek Treatment scale and the Value and Need in Seeking Treatment scale. Items are be assessed on a four-point Likert scale ranging from "disagree" (score 0) to "agree" (score 3). Scale scores of the Openness scale are calculated by summing scale items, with higher scores indicating more openness towards professional help. Scores on the Value scale items were reversed and then summed such that higher scores indicated less stigmatizing attitudes towards treatment. A more detailed description of the survey instrument can be found elsewhere (Coppens et al., 2013). Finally, at wave 2 all participants were asked whether they had heard about the OSPI-Europe depression awareness campaign.

\subsection{Participants}

In each control and intervention region, a stratified sample of circa 500 adult subjects $(18+)$ was selected using the random digit dialling method and tested before the campaign was launched (wave 1). Using the same selection procedure, circa 500 other respondents were selected and assessed in each region after the launch of the campaign (wave 2). Each sample was representative to the local population in terms of gender and age distribution. All subjects were contacted by telephone and asked to participate in the interview. At wave 2, the response rate was $31.4 \%$ (see Table 2), which was comparable to the response rate at wave 1 (mean 30.7) (see Coppens et al., 2013). The total sample of wave 1 consisted of 4011 participants and of wave 2 of 4004 participants.

\subsection{Ethical approval}

The OSPI-Europe project was executed in accordance with the declaration of Helsinki (WMA, 2000). Ethical approval for the general population survey in the intervention and control regions in Germany, Hungary, Portugal and Ireland was granted by the ethical research

Table 2

Overview of regions and survey characteristics.

\begin{tabular}{|c|c|c|c|c|c|c|c|}
\hline & & \multirow{2}{*}{$\begin{array}{l}\text { Response rate (Wave } 2 \text { ) after a atin } \\
\%\end{array}$} & \multirow{2}{*}{$\begin{array}{l}\text { No. of inhabitants } \\
\text { inhabitants }\end{array}$} & \multicolumn{2}{|c|}{ Campaign duration } & \multicolumn{2}{|l|}{ Survey period } \\
\hline & & & & Start & End & Wave 1 & Wave 2 \\
\hline \multicolumn{8}{|l|}{ Germany } \\
\hline Intervention region & Leipzig & 20.5 & 516430 & June 2009 & March 2011 & May 2009 & December 2010 \\
\hline Control region & Magdeburg & 21.2 & 230540 & & & May 2009 & December 2010 \\
\hline \multicolumn{8}{|l|}{ Hungary } \\
\hline Intervention region & Miskolc & 39.2 & 171096 & January 2010 & June 2011 & December 2009 & June 2011 \\
\hline Control region & Szeged & 39.0 & 167039 & & & December 2009 & June 2011 \\
\hline \multicolumn{8}{|l|}{ Ireland } \\
\hline Intervention region & Limerick & 22.1 & 184085 & January 2010 & June 2011 & December 2009 & December 2011 \\
\hline Control region & Galway & 20.4 & 231670 & & & December 2009 & December 2011 \\
\hline \multicolumn{8}{|l|}{ Portugal } \\
\hline Intervention region & Amadora & 45.7 & 175872 & April 2010 & September 2011 & February 2010 & December 2011 \\
\hline Control region & Almada & 42.7 & 174030 & & & February 2010 & December 2011 \\
\hline \multicolumn{8}{|l|}{ Mean } \\
\hline Intervention region & & 31.9 & 261870 & & & & \\
\hline Control region & & 30.8 & 200819 & & & & \\
\hline Total & & 31.4 & 231344 & & & & \\
\hline
\end{tabular}




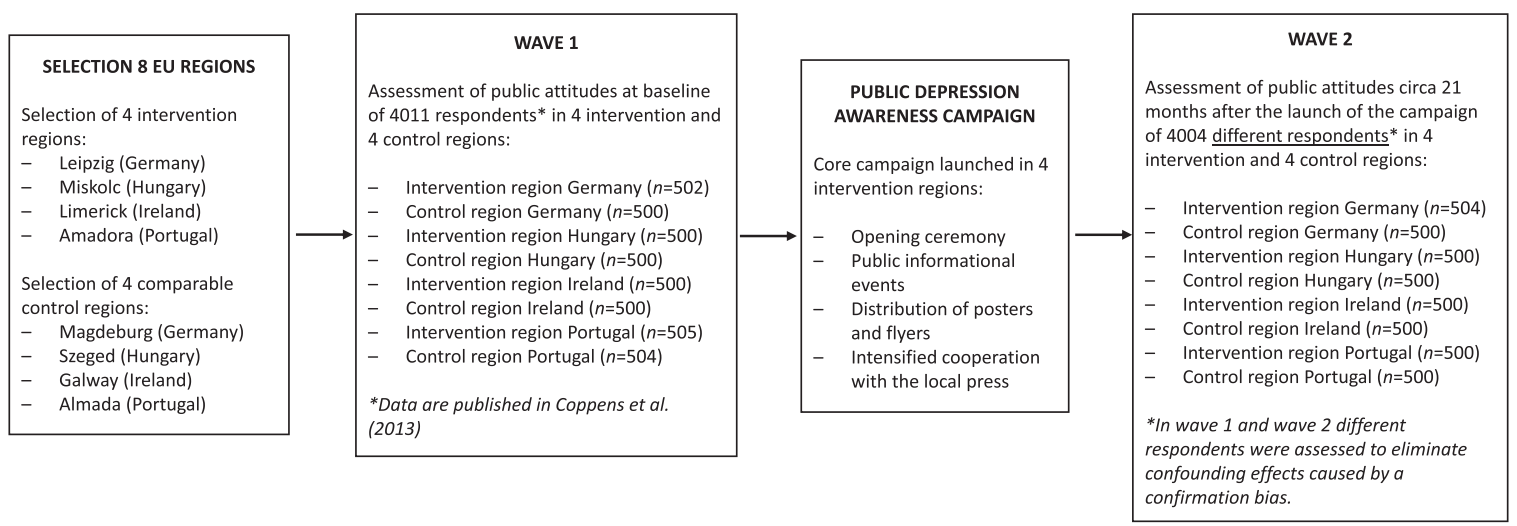

Fig. 1. Overview of the study design and selection of respondents at wave 1 and wave 2 .

committees of all participating countries.

\subsection{Data analysis}

Statistical analyses were carried out using SPSS 22.0. First, Chi square tests were performed to investigate whether the campaign was noticed more frequently in the intervention regions than in the control regions and it was tested whether several socio-demographic characteristics were associated with increased awareness of the campaign. Second, to examine whether the campaign changed the respondent's attitudes, an analysis of variance on each of the four outcome subscales was carried out with the variables wave (wave 1 vs. wave 2), region (intervention vs. control) and country (Germany vs. Hungary vs. Ireland vs. Portugal) being entered as between-subjects factors. Third, an analysis of variance was conducted on each of the four outcome variables, to examine whether respondents of the intervention regions who were queried at wave 2 and were aware of the campaign (aware intervention group) showed more positive attitudes toward depression and professional help than respondents of the control regions who were queried at wave 2 and were not exposed to the campaign (control group). The variables country and awareness were entered as betweensubjects factors. Additionally, socio-demographic characteristics of the two samples in each region were examined by exploring descriptive statistics.

\section{Results}

\subsection{Sample description}

Table 3 displays the participants' characteristics in the intervention and control regions of both samples. Respondents from intervention versus control regions were comparable regarding socio-economic characteristics and previous exposure to depression, self-harm or suicide in close family members or friends. Only the marital status of respondents was significantly different in both region types with more respondents living alone in the intervention regions $\chi^{2}(5)=14.52$, $\mathrm{p}<0.05$

Nearly half of the respondents (46\%) had experienced depression in

Table 3

Participants' characteristics (in \%).

\begin{tabular}{|c|c|c|c|c|c|c|c|c|}
\hline & \multicolumn{2}{|l|}{ Germany } & \multicolumn{2}{|l|}{ Hungary } & \multicolumn{2}{|l|}{ Ireland } & \multicolumn{2}{|l|}{ Portugal } \\
\hline & Intervention & Control & Intervention & Control & Intervention & Control & Intervention & Control \\
\hline $\mathrm{N}$ habitants & 516430 & 230540 & 171096 & 167039 & 184085 & 231670 & 261870 & 200819 \\
\hline $\mathrm{N}$ respondents first wave & 502 & 500 & 500 & 500 & 500 & 500 & 505 & 504 \\
\hline $\mathrm{N}$ respondents second wave & 504 & 500 & 500 & 500 & 500 & 500 & 500 & 500 \\
\hline Female & 51.8 & 51.8 & 54.0 & 51.8 & 48.8 & 48.8 & 53.0 & 52.6 \\
\hline \multicolumn{9}{|l|}{ Age } \\
\hline Mean age (SD) & $48.8(18.3)$ & $49.5(18.1)$ & $47.4(17.7)$ & $47.4(18.2)$ & 44.5 (15.9) & $45.5(15.5)$ & $47.3(18.6)$ & $48.1(18.3)$ \\
\hline$<40$ years & 36.9 & 34.0 & 39.6 & 40.8 & 49.6 & 45.4 & 40.2 & 38.6 \\
\hline 40 to 59 years & 32.1 & 32.8 & 33.0 & 32.6 & 31.6 & 33.4 & 34.4 & 33.8 \\
\hline$>59$ years & 31.0 & 33.2 & 27.4 & 26.6 & 18.8 & 21.2 & 25.4 & 27.6 \\
\hline \multicolumn{9}{|l|}{ Years of schooling } \\
\hline Mean years $( \pm S D)$ & $12.4(2.8)$ & $12.7(2.8)$ & $14.8(3.8)$ & $14.7(3.5)$ & $13.6(4.2)$ & $13.4(4.4)$ & $11.2(5.6)$ & $11.8(5.6)$ \\
\hline$<7 \mathrm{y}$ & 0.0 & 0.0 & 0.4 & 0.8 & 6.8 & 7.2 & 26.3 & 20.8 \\
\hline $7-12 y$ & 62.9 & 54.0 & 35.2 & 34.8 & 34.6 & 37.8 & 38.1 & 35.4 \\
\hline $13-16$ y & 29.0 & 36.6 & 36.2 & 35.8 & 34.0 & 30.8 & 16.8 & 24.8 \\
\hline$>16 y$ & 8.1 & 9.4 & 28.2 & 28.6 & 24.6 & 24.2 & 18.8 & 19.0 \\
\hline \multicolumn{9}{|l|}{ Marital status } \\
\hline Living with partner & 55.6 & 58.0 & 52.0 & 54.8 & 65.6 & 67.8 & 52.8 & 56.8 \\
\hline Living alone & 44.4 & 42.0 & 48.0 & 45.2 & 34.4 & 32.2 & 47.2 & 43.2 \\
\hline \multicolumn{9}{|l|}{ Occupational status } \\
\hline Working & 90.7 & 94.0 & 94.6 & 95.0 & 88.0 & 87.6 & 90.8 & 91.2 \\
\hline Unemployed & 9.3 & 6.0 & 5.4 & 5.0 & 12.0 & 12.4 & 9.2 & 8.8 \\
\hline \multicolumn{9}{|c|}{ Experience with mental ill-health in relatives } \\
\hline Depression & 31.2 & 31.2 & 40.0 & 39.0 & 49.6 & 45.4 & 62.8 & 66.0 \\
\hline Deliberate self-harm & 11.1 & 6.0 & 13.8 & 13.4 & 28.8 & 21.4 & 23.4 & 32.6 \\
\hline Suicide & 6.7 & 5.0 & 14.4 & 14.6 & 24.4 & 21.6 & 16.8 & 18.6 \\
\hline
\end{tabular}


close family members or friends, and a minority had dealt with deliberate self-harm $(18 \%)$ or suicide $(15 \%)$ in relatives in the past. The characteristics of the respondents in wave 2 are comparable to those of the characteristics of the respondents in wave 1 which are described in a different paper (Coppens et al., 2013).

\subsection{Campaign's visibility}

The campaign was more visible in the intervention regions than in the control regions $\left(\chi^{2}(1)=86.6, p<0.001\right)$. More specifically, prior to the launch of the campaign $8.8 \%$ of the respondents in the intervention regions and $8.2 \%$ of the respondents in the control regions reported that they had heard about the campaign. At the post assessment the percentages were $17.3 \%$ versus $7.6 \%$ respectively. The number of people that had noticed the campaign significantly differed across countries $\left(\chi^{2}(3)=78.7, \mathrm{p}<0.001\right)$. The observed frequencies show that the campaign was considerably more visible in Germany (25.8\%) and Portugal (23.6\%) than in Hungary (8.6\%) and Ireland (11.2\%). No significant gender differences among those aware of the campaign were found $\left(\chi^{2}(1)=0.0, p>0.05\right)$, whereas age was of significant influence $\left(\chi^{2}(2)=6.5, \mathrm{p}<0.05\right)$. People younger than 40 years had heard the campaign less frequently $(14.8 \%)$ than people of $40-59$ years old $(19.0 \%)$ and people over 59 (19.3\%). Moreover, the visibility of the campaign was highest among respondents with less than 7 years of education (19.6\%) than among respondents with 7-12 years of education (12.4\%), 13-16 years of education (11.4\%) or more than 16 years of education $(11.4 \%)\left(\chi^{2}(3)=16.71, p<0.01\right)$.

\subsection{Respondent's attitudes after the campaign}

\subsubsection{Personal stigma scale}

Results showed significant main effects of wave $(\mathrm{F}(1,7999)=93.4$, $\mathrm{p}<0.001)$, region $(\mathrm{F}(1,7999)=7.4, \mathrm{p}<0.01)$, and country $(\mathrm{F}(3,7999)$ $=174.7, \mathrm{p}<0.001)$. Overall, respondents questioned at wave 2 (Estimated mean $(\mathrm{EM})=22.2$ and standard error $(\mathrm{SE})=0.09)$ showed more positive attitudes toward depression than respondents questioned at wave $1(\mathrm{EM}=23.5$ and $\mathrm{SE}=0.09)$. Also, respondents in the control regions $(\mathrm{EM}=22.7, \mathrm{SE}=0.09)$ showed more positive attitudes than respondents in the intervention regions $(\mathrm{EM}=23.0, \mathrm{SE}=0.09)$. Finally, Hungarian people (EM $=25.0, \mathrm{SE}=0.13$ ) showed overall the least favourable attitudes toward depression whereas Irish people (EM $=21.0, \quad \mathrm{SE}=0.13$ ) showed the most favourable attitudes. Importantly, we found a significant two-way interaction between wave and region, $(\mathrm{F}(1,7999)=5.2, \mathrm{p}<0.05)$ : compared to wave 1 , there was a significant decrease in personal stigma at wave 2 , both in the intervention and the control regions with respectively $F(1,7999)$ $=66.51, \mathrm{p}<0.001$ and $\mathrm{F}(1,7999)=25.33 \mathrm{p}<0.001$. Importantly, the effect was more pronounced in the intervention regions than in the control regions, suggesting that the campaign induced a significant reduction in personal stigma. The three-way interaction between time, region and country yielded no significance $(F(3,7999)=0.35$, $p>0.05$ ), suggesting that the effect of the campaign was comparable in the four countries.

\subsubsection{Perceived stigma scale}

Results showed significant main effects of wave $(\mathrm{F}(1,7999)=4.4$, $\mathrm{p}<0.05)$ and country $(\mathrm{F}(3,7999)=252.0, \mathrm{p}<0.001)$. Respondents questioned at wave $2(\mathrm{EM}=28.7, \mathrm{SE}=0.10)$ showed less perceived stigma than respondents questioned at wave 1 ( $\mathrm{EM}=28.9, \mathrm{SE}=0.9$ ). Furthermore, the highest perceived stigma was registered in Germany $(\mathrm{EM}=30.9, \mathrm{SE}=0.14)$ and the lowest in Ireland $(\mathrm{EM}=25.8, \mathrm{SE}$ $=0.14)$.

The two-way interaction between wave and region reached no significance $(\mathrm{F}(1,7999)=2.1, \mathrm{p}>0.05)$, suggesting that the decrease in perceived stigma was comparable in both the intervention and control regions.
Importantly, the three-way interaction between wave, region, and country reached significance $(\mathrm{F}(3,7999)=2.7, \mathrm{p}<0.05)$, suggesting that the effect of campaign varied across countries. In the intervention region of Ireland a significant reduction of perceived stigma was observed at wave $2(\mathrm{~F}(1,1996)=7.8, \mathrm{p}<0.01),(\mathrm{M}=24.1, \mathrm{SE}$ $=0.27)$ as compared to wave $1(\mathrm{M}=27.3, \mathrm{SE}=0.27)$. By contrast, in the Irish control region perceived stigma did not differ at wave 1 and wave 2 . In the other three countries no such interaction between wave and region occurred (with $\mathrm{F}<1$ for all three contrasts).

\subsubsection{Openness scale}

Results showed significant main effects of wave $(F(1,7997)=90.5$, $\mathrm{p}<0.001)$ and country $(\mathrm{F}(3,7997)=530.3, \mathrm{p}<0.001)$. The respondents questioned at wave $2(\mathrm{EM}=10.4, \mathrm{SE}=0.05)$ showed more openness toward seeking professional help than respondents questioned at wave $1(\mathrm{EM}=9.8$ and $\mathrm{SE}=0.05)$. Generally, Hungarian people (EM $=8.3$, SE $=0.07$ ) were the least open toward professional help and Portuguese people (EM $=12.0, \mathrm{SE}=0.07)$ the most.

The two-way interaction between wave and region yielded no significance $(F(1,7997)=3.5, p>0.05)$, suggesting that the increase in openness at wave 2 was comparable in both the intervention and control regions. Importantly, the three-way interaction between wave, region and country was significant $(\mathrm{F}(3,7997)=4.5, \mathrm{p}<0.01)$, suggesting that the effect of campaign varied across countries. We found in the control region of Germany a significant increase in openness toward seeking professional help at wave $2(\mathrm{M}=10.4, \mathrm{SD}=2.8)$ as compared to wave $1(\mathrm{M}=9.1, \mathrm{SD}=2.8)(\mathrm{F}(1,2002)=14.3, \mathrm{p}<0.001)$, whereas no increase between wave 1 and wave 2 was observed in the German intervention region. In Hungary, Ireland, and Portugal, the two-way interaction between wave and region reached no significance, with respectively $\mathrm{F}(1,1994)=1.2, \mathrm{p}>0.05, \mathrm{~F}(1,1996)=3.0, \mathrm{p}>0.05$ and $\mathrm{F}(1,2005)=0.14, \mathrm{p}>0.05$.

\subsubsection{Value scale}

Results showed significant main effects of wave $(\mathrm{F}(1,7989)=49.9$, $\mathrm{p}<0.001)$ and country $(\mathrm{F}(3,7989)=474.5, \mathrm{p}<0.001)$. Overall, respondents questioned at wave $2(\mathrm{EM}=8.1, \mathrm{SE}=0.05)$ considered professional help to be more valuable than respondents questioned at wave $1(\mathrm{EM}=7.6, \mathrm{SE}=0.05)$. German people scored the highest value $(\mathrm{EM}=9.3, \mathrm{SE}=0.07)$ and Hungarian people the lowest $(\mathrm{EM}=5.7, \mathrm{SE}$ $=0.07$ ). The two-way interaction between wave and region reached no significance $(F(1,7989)=3.0, p>0.05)$, suggesting that the increase in value was comparable in both the intervention and control regions. The three-way interaction between time, region and country yielded no significance $(F(3,7989)=0.41, p>0.05)$ suggesting that the effect of campaign was comparable in the four countries.

\subsubsection{Changes in attitudes in respondents who were aware of the campaign}

An analysis of variance was conducted on each of the four outcome variables, to examine whether respondents of the intervention regions who were queried at wave 2 and were aware of the campaign (aware intervention group) showed more positive attitudes toward depression and professional help than respondents of the control regions who were queried at wave 2 and were not exposed to the campaign (control group). The variables country and awareness were entered as betweensubjects factors.

\subsubsection{Personal Stigma subscale}

The main effect of awareness was not significant $(\mathrm{F}(1,3996)=2.51$, $\mathrm{p}=0.11$ ), suggesting that respondents of the intervention regions who were aware of the campaign had similar attitudes toward depression than respondents in the control regions. Importantly, the interaction between awareness and country did reach significance $(\mathrm{F}(3,3996)$ =7.33, p < 0.001). Planned comparisons revealed that only in Germany respondents of the intervention region who were aware of the campaign showed more positive attitudes compared to control 
Table 4

Estimated means and standard errors at baseline (wave 1) and after implementation of the public campaign (wave 2) on the four subscales.

\begin{tabular}{|c|c|c|c|c|c|c|c|c|}
\hline & \multicolumn{2}{|l|}{ Germany } & \multicolumn{2}{|l|}{ Hungary } & \multicolumn{2}{|l|}{ Ireland } & \multicolumn{2}{|l|}{ Portugal } \\
\hline & Intervention & Control & Intervention & Control & Intervention & Control & Intervention & Control \\
\hline \multicolumn{9}{|c|}{ Personal Stigma subscale } \\
\hline Wave 1 & $24.14(0.27)$ & $22.58(0.27)$ & $25.52(0.27)$ & $24.62(0.27)$ & $22.29(0.27)$ & $21.92(0.27)$ & $23.38(0.27)$ & $23.56(0.27)$ \\
\hline Wave 2 & $21.17(0.27)$ & $20.22(0.27)$ & $25.16(0.27)$ & $24.87(0.27)$ & $19.57(0.27)$ & $20.18(0.27)$ & $23.10(0.27)$ & $23.50(0.27)$ \\
\hline \multicolumn{9}{|c|}{ Perceived Stigma subscale } \\
\hline Wave 1 & $30.84(0.27)$ & $31.24(0.27)$ & $28.89(0.27)$ & $28.54(0.27)$ & $27.30(0.27)$ & $26.58(0.27)$ & $28.99(0.27)$ & $29.16(0.27)$ \\
\hline Wave 2 & $30.63(0.27)$ & $30.92(0.27)$ & $29.86(0.27)$ & $29.88(0.27)$ & $24.12(0.27)$ & $25.07(0.27)$ & $29.46(0.27)$ & $29.29(0.27)$ \\
\hline \multicolumn{9}{|c|}{ Openness subscale } \\
\hline Wave 1 & $9.52(0.14)$ & $9.08(0.14)$ & $7.94(0.14)$ & $8.08(0.14)$ & $9.94(0.14)$ & $9.57(0.14)$ & $11.96(0.14)$ & $11.91(0.14)$ \\
\hline Wave 2 & $9.85(0.14)$ & $10.37(0.14)$ & $8.59(0.14)$ & $8.42(0.14)$ & $10.82(0.14)$ & $10.92(0.14)$ & $12.16(0.14)$ & $12.00(0.14)$ \\
\hline \multicolumn{9}{|c|}{ Value subscale } \\
\hline Wave 1 & $7.76(0.14)$ & $8.12(0.14)$ & $5.97(0.14)$ & $5.71(0.14)$ & $8.66(0.14)$ & $8.63(0.14)$ & $8.26(0.14)$ & $7.92(0.14)$ \\
\hline Wave 2 & $10.41(0.14)$ & $10.99(0.14)$ & $5.53(0.14)$ & $5.53(0.14)$ & $8.41(0.14)$ & $8.41(0.14)$ & $7.83(0.14)$ & $7.96(0.14)$ \\
\hline
\end{tabular}

participants $(\mathrm{F}(1,3996)=22.39, \mathrm{p}<0.001)($ Table 4$)$.

\subsubsection{Perceived Stigma subscale}

Perceived stigma was significantly lower for respondents of the intervention regions who were aware of the campaign $(\mathrm{EM}=27.96, \mathrm{SE}$ $=0.28)$ than for those in the control regions $(\mathrm{EM}=28.72, \mathrm{SE}=0.10)(\mathrm{F}$ $(1,3996)=6.30, \mathrm{p}<0.05)$. Furthermore, the two-way interaction between awareness and country was significant $(\mathrm{F}(3,3996)=3.75$, $\mathrm{p}<0.05$ ) suggesting that this effect differed across countries (Table 4). Planned contrasts further revealed that the effect of awareness was significant in Ireland $(\mathrm{F}(1,3996)=10.01, \mathrm{p}<0.01)$ but not in the other three countries with $(\mathrm{F}(1,3996)=3.08, \mathrm{p}=0.08)$ for Germany, $(\mathrm{F}<1)$ for Hungary, and $(\mathrm{F}(1,3996)=1.36, \mathrm{p}=0.24)$ for Portugal.

\subsubsection{Openness subscale}

According to the ANOVA, respondents of the intervention regions who noticed the campaign (EM $=10.77, \mathrm{SE}=0.14$ ) reported significantly more openness toward seeking professional help than respondents in the control regions $(\mathrm{EM}=10.33, \mathrm{SE}=0.05)(\mathrm{F}(1,3995)=8.57$, $\mathrm{p}<0.01$ ). The interaction of awareness with country yielded no significance $(F<1)$, suggesting that this effect was comparable for all four countries.

\subsubsection{Value subscale}

With respect to perceived value of professional help, no difference was found between respondents of the intervention regions who were aware of the campaign versus respondents of the control regions $(\mathrm{F}<1)$. The two-way interaction between awareness and country however did reach significance $(\mathrm{F}(3,3992)=3.80, \mathrm{p}<0.05)$. Additional analyses showed that in Germany respondents of the intervention region who were aware of the campaign set the value of professional help higher than respondents of the control region ( $F$ $(1,3992)=3.99, p<0.05)$ (Table 4). In the other three countries a similar effect of awareness was not observed (with $\mathrm{F}(1,3992)=2.51$, $\mathrm{p}=0.11)$ for Hungary, $(\mathrm{F}(1,3992)=3.03, \mathrm{p}=0.08)$ for Ireland, and $(\mathrm{F}$ $(1,3992)=1.99, \mathrm{p}=0.16)$ for Portugal.

\section{Discussion}

The OSPI-Europe public awareness campaign was effective to reach up to $25.8 \%$ (Germany) of the general public in the intervention region (mean across all countries in intervention regions: $17.3 \%$ ). Compared to the reach of previous and comparable awareness campaigns (e.g. 7.3\% in a German sample (Makowski et al., 2016a)), this can be considered as remarkably high. With the overall reach of the general public being higher at wave 2 than at wave 1, the campaign was successful in raising attention to the topic. However, the campaign was considerably more visible in Germany and Portugal than in Hungary and Ireland. The number of public events was highest in Germany (45) and the lowest in Ireland (1) which may serve as an explanation for the strong difference in visibility between these two countries and should be taken into account when interpreting the country differences. In Portugal, the percentage of participants reporting experience with depression, deliberate self-harm and suicide in relatives, was the highest (66\%) compared to all other countries and might have contributed to more public alertness to the campaigns target messages. It has been shown previously that people self-reporting a prior history of depression show both lower personal stigma/social distance and lower perceived stigma (Griffiths et al., 2008). In Hungary, the campaign was launched in the year of the elections of the members of the parliament (in April 2011) and the members of the local governments (in October 2011) and the intervention region was hit by a major flood. These circumstances may have drawn public attention away from the campaign activities and impeded the desired effects. In Ireland, another mental health awareness campaign (Your Mental Health) was implemented at national level at the same time, targeting the Irish intervention and control region. This additional campaign may have overshadowed the visibility of the OSPI campaign. All contextual factors were studied by a process evaluation which accompanied the OSPI-Europe project. These results will be published elsewhere. Additionally, visibility likely depends on a variety of factors, such as the channels used for distributing the campaign's messages. The OSPI campaign mainly relied on classical dissemination channels (flyer, poster etc.), which might partly explain why people aged 40 and older noticed it more often. Visibility was furthermore associated with educational level: the campaign was most visible for persons with fewer years of education.

Respondent's personal stigma towards depression differed significantly across countries with Hungarian people showing the least favourable attitudes toward depression whereas Irish people had the most favourable attitudes after the campaign (wave 2). In Ireland, the intention of the OSPI awareness campaign may have been reinforced by another national mental health awareness campaign (Your Mental Health) which was implemented simultaneously. Personal stigma was already found to be the highest among Hungarian respondents compared to all other countries at wave 1 and taking into account the weak visibility in Hungary, both these factors might have impeded the effect on personal attitudes toward depression (Coppens et al., 2013).

Importantly, respondents in the intervention regions showed less personal depression stigma than respondents in the control regions after the campaign. This is in line with previous findings on campaigns that can improve knowledge and awareness in the population in the short term (Dumesnil and Verger, 2009).

The effect of the campaign on perceived stigma varied significantly across countries: In the intervention region of Ireland, perceived stigma 
was significantly decreased at wave 2 with Ireland being the only country where the intervention programme was successful in reducing perceived stigma. Since at wave 1 , perceived stigma was already found to be the lowest in Ireland compared to all other countries, we concluded a rather reinforcing environment for the campaign and thus, the strongest effects in the Irish intervention region. According to these findings, perceived stigma seems to be more difficult to target than personal stigma by a public awareness campaign.

The effect of the campaign on openness towards professional help differed significantly across countries. Contrary to our expectations, only in the control region of Germany a significant effect of campaign was observed with more openness toward professional help at wave 2. Especially in Germany, the suicide of the national goalkeeper Robert Enke in 2009 accompanied by broad and mainly appropriate media coverage on suicide and depression might have led to increased depression awareness and openness toward help-seeking in the control region as well as in all over Germany. While reports about the suicide itself led to national and international copycat effects (Hegerl et al., 2013; Koburger et al., 2015), stigma seems not to be influenced by such events to a great extent. Recent findings point to rather small effects on increasing public stigma towards mental illness after significant single events: the crash of a Germanwings airplane in Germany (2015), where a mentally ill pilot purposefully provoked the crash of the airbus along with approximately 150 passengers or a celebrity suicide in Germany (2009) (dem Knesebeck et al., 2015; Schomerus et al., 2015).

Value of professional help was increased in respondents at wave 2 compared to wave 1 . After the campaign, value was only influenced by country and was set highest by German and lowest by Hungarian respondents.

Generally, respondents of the intervention region at wave 2 who were aware of the campaign reported more openness toward seeking professional help than respondents who were unaware of it, suggesting that the campaign had a positive effect on help-seeking (behaviour) across countries. This finding is novel compared to a majority of previous studies in the field that did not examine a change in the tendency to seek professional help (e.g. Dumesnil and Verger, 2009; Clement et al., 2013).

Further, we found significant differences between aware respondents in the intervention regions compared to the control region to the queries at wave 2. In Germany, respondents who noticed the campaign showed less personal stigma attitudes and set the value of professional help higher compared to those in the German control regions. This destigmatizing effect of the campaign only in Germany could be explained by its comparatively high intensity in the intervention region (The number of flyers and public events was the highest compared to all other intervention regions, see Table 1). Again, the campaigns effect on perceived stigma for individuals of the intervention region who were aware of the campaign was solely significant in Ireland.

Multi-level campaigns like OSPI-Europe have been recommended by the WHO (World Health Organization (WHO), 2014) as they can improve knowledge and awareness about mental health issues. Although effects on attitudes have been shown to be mostly small to modest (Dumesnil and Verger, 2009), these effects should not be minimalized. Within OSPI-Europe, it has been shown that a public relations campaign as one component of a multi-level programme has the potential to provoke synergistic and even catalyst effects (Harris et al., 2016). This is in line with extended experiences from the European Alliance Against Depression (www.eaad.net) over the past decade (Hegerl and Kohls, 2016): Experiences from different intervention regions in Europe show that campaigns can motivate people with psychiatric disorders to seek help and in addition generate the impression that there is support, acceptance and understanding in the general public for depressed patients, to name one example. Groundwork for synergistic effects can particularly be fostered by conducting an opening ceremony or visible launch event (Harris et al., 2013, 2016).

\subsection{Strengths and limitations}

Strengths of this study are the standardized methodological approach applied across different European countries including the use of internationally validated instruments and native language interviewers as well as the fairly equal gender and age balance across the different countries. It also represents one of the few studies conducted in a controlled design and overcoming the unequal distribution of intervention sites across Western Europe (Evans-Lacko et al., 2014) by including respondents from a Hungarian population.

Despite these strengths, there are also some methodological limitations to be taken into account. Self-report measures might have led to a report bias, like social desirability bias which is especially crucial when assessing attitudes and stigma. No causal inferences can be drawn from the results due to the cross-sectional design. Compared to other investigations in the field, the OPSI-Europe intervention period might have been too short (e.g. (Paykel et al., 1997; Jorm et al., 2005) to provoke clearer results. But, despite great efforts, other comparable and longer lasting campaigns (Defeat Depression; beyondblue; Like Minds, Like Mine) have barely been visible to the public, and population awareness of depression and treatment options increased only slightly.

\section{Conclusion}

The OSPI-Europe suicide prevention programme including a public relation campaign was successful in being visible to the public in the intervention regions in four European countries. The pre campaign levels of depression stigma (personal and perceived) as well as the openness towards professional help and the perceived value of professional help improved at the time of post-assessments. Besides some ambiguous results and the detected improvements in both the intervention and control regions, the results demonstrate a more pronounced effect for perceived stigma and openness toward seeking professional in respondents who were aware of the campaign. Public awareness campaigns aiming to improve depression awareness and mental health literacy are essential to optimize depression care. Since important synergistic effects can arise, campaigns should be integrated as one component into a multi-level mental health promotion or suicide prevention programmes, with awareness campaigns being conducted. In many regions in Europe and beyond such 4-level interventions including a public awareness campaign are still ongoing (www.eaad. net) with the combined aims of improving the care for depressed

Table 5

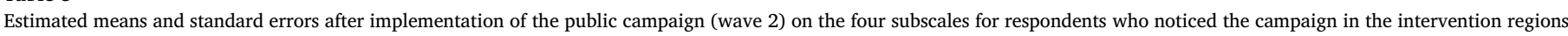
('Aware Intervention') versus those of the control groups ('Control').

\begin{tabular}{|c|c|c|c|c|c|c|c|c|}
\hline & \multicolumn{2}{|l|}{ Germany } & \multicolumn{2}{|l|}{ Hungary } & \multicolumn{2}{|l|}{ Ireland } & \multicolumn{2}{|l|}{ Portugal } \\
\hline & Aware Intervention & Control & Aware Intervention & Control & Aware Intervention & Control & Aware Intervention & Control \\
\hline Personal Stigma subscale & $18.65(0.47)$ & $21.06(0.20)$ & $26.18(0.65)$ & $24.91(0.19)$ & $19.20(0.62)$ & $19.94(0.19)$ & $23.32(0.43)$ & $23.29(0.20)$ \\
\hline Perceived Stigma subscale & $29.99(0.48)$ & $30.91(0.20)$ & $29.37(0.67)$ & $29.92(0.20)$ & $22.65(0.64)$ & $24.78(0.20)$ & $29.84(0.44)$ & $29.27(0.21)$ \\
\hline Openness subscale & $10.61(0.24)$ & $10.02(0.10)$ & $8.95(0.34)$ & $8.47(0.10)$ & $10.90(0.32)$ & $10.87(0.10)$ & $12.62(0.22)$ & $11.96(0.10)$ \\
\hline Value subscale & $11.18(0.26)$ & $10.62(0.11)$ & $4.97(0.37)$ & $5.58(0.11)$ & $8.99(0.35)$ & $8.35(0.11)$ & $7.59(0.24)$ & $7.96(0.11)$ \\
\hline
\end{tabular}


patients and the prevention of suicidal behaviour (Hegerl et al., 2013). (Table 5).

\section{References}

Akroyd, S., Wyllie, A., 2003. People with experience of mental illness: Perceptions of the "Like Minds" Project. Appendix 3, survey comment 051. Phoenix Research, Auckland. Anderson, I.M., 2000. Selective serotonin reuptake inhibitors versus tricyclic antidepressants. A meta-analysis of efficacy and tolerability. J. Affect. Disord. 58, 19-36.

Aromaa, E., Tolvanen, A., Tuulari, J., Wahlbeck, K., 2011. Personal stigma and use of mental health services among people with depression in a general population in Finland. BMC Psychiatry 11, 52.

Barney, L.J., Griffiths, K.M., Jorm, A.F., Christensen, H., 2006. Stigma about depression and its impact on help-seeking intentions. Aust. N. Z. J. Psychiatry 40, 51-54.

Baumeister, H., Härter, M., 2007. Prevalence of mental disorders based on general population surveys. Social. Psychiatry Psychiatr. Epidemiol. 42, 537-546.

Braunholtz, S., Davidson, S., King, S., 2004. Well? What do you think? The Second National Scottish Survey of Public Attitudes to Mental Health, Well Being and Mental Health Problems, Edinburgh.

Calear, A.L., Griffiths, K.M., Christensen, H., 2011. Personal and perceived depression stigma in Australian adolescents. Magnitude and predictors. J. Affect. Disord. 129, 104-108.

Chisholm, D., Sweeny, K., Sheehan, P., Rasmussen, B., Smit, F., Cuijpers, P., Saxena, S., 2016. Scaling-up treatment of depression and anxiety. A global return on investment analysis. Lancet Psychiatry.

Cipriani, A., Furukawa, T.A., Salanti, G., Geddes, J.R., Higgins, J.P.T., Churchill, R., Watanabe, N., Nakagawa, A., Omori, I.M., McGuire, H., Tansella, M., Barbui, C., 2009. Comparative efficacy and acceptability of 12 new-generation antidepressants. A multiple-treatments meta-analysis. Lancet 373, 746-758.

Clement, S., Schauman, O., Graham, T., Maggioni, F., Evans-Lacko, S., Bezborodovs, N., Morgan, C., Rüsch, N., Brown, J.S.L., Thornicroft, G., 2015. What is the impact of mental health-related stigma on help-seeking? A systematic review of quantitative and qualitative studies. Psychol. Med. 45, 11-27.

Coppens, E., van Audenhove, C., Scheerder, G., Arensman, E., Coffey, C., Costa, S., Koburger, N., Gottlebe, K., Gusmão, R., O'Connor, R., Postuvan, V., Sarchiapone, M., Sisask, M., Székely, A., van der Feltz-Cornelis, C., Hegerl, U., 2013. Public attitudes toward depression and help-seeking in four European countries baseline survey prior to the OSPI-Europe intervention. J. Affect. Disord. 150, 320-329.

Crisp, A., Gelder, M., Goddard, E., Meltzer, H., 2005. Stigmatization of people with mental illnesses: a follow-up study within the changing minds campaign of the Royal College of Psychiatrists. World Psychiatry.: Off. J. World Psychiatr. Assoc. (WPA) 4, 106-113.

dem Knesebeck, O., von, Mnich, E., Angermeyer, M.C., Kofahl, C., Makowski, A., 2015. Changes in depression stigma after the Germanwings crash - findings from German population surveys. J. Affect. Disord. 186, 261-265.

DeRubeis, R.J., Hollon, S.D., Amsterdam, J.D., Shelton, R.C., Young, P.R., Salomon, R.M., O'Reardon, J.P., Lovett, M.L., Gladis, M.M., Brown, L.L., Gallop, R., 2005. Cognitive therapy vs medications in the treatment of moderate to severe depression. Arch. General. Psychiatry 62, 409-416.

Dietrich, S., Mergl, R., Rummel-Kluge, C., 2014. Personal and perceived stigmatization of depression. A comparison of data from the general population, participants of a depression congress and job placement officers in Germany. Psychiatry Res. 220 598-603.

Dietrich, S., Mergl, R., Freudenberg, P., Althaus, D., Hegerl, U., 2010. Impact of a campaign on the public's attitudes towards depression. Health Educ. Res. 25, $135-150$.

Dumesnil, H., Verger, P., 2009. Public awareness campaigns about depression and suicide: a review. Psychiatr. Serv. 60, 1203-1213.

Eisenberg, D., Downs, M.F., Golberstein, E., Zivin, K., 2009. Stigma and help seeking for mental health among college students. Med. care Res. Rev.: MCRR 66, 522-541.

Evans-Lacko, S., Brohan, E., Mojtabai, R., Thornicroft, G., 2012. Association between public views of mental illness and self-stigma among individuals with mental illness in 14 European countries. Psychol. Med. 42, 1741-1752.

Evans-Lacko, S., Courtin, E., Fiorillo, A., Knapp, M., Luciano, M., Park, A.-L., Brunn, M., Byford, S., Chevreul, K., Forsman, A.K., Gulacsi, L., Haro, J.M., Kennelly, B., Knappe, S., Lai, T., Lasalvia, A., Miret, M., O'Sullivan, C., Obradors-Tarrago, C., Rusch, N., Sartorius, N., Svab, V., van Weeghel, J., van Audenhove, C., Wahlbeck, K., Zlati, A., McDaid, D., Thornicroft, G., 2014. The state of the art in European research on reducing social exclusion and stigma related to mental health: a systematic mapping of the literature. Eur. Psychiatry.: J. Assoc. Eur. Psychiatr. 29, 381-389.

Fernández, A., Haro, J.M., Martinez-Alonso, M., Demyttenaere, K., Brugha, T.S., Autonell, J., Girolamo, G., de, Bernert, S., Lépine, J.P., Alonso, J., 2007. Treatment adequacy for anxiety and depressive disorders in six European countries. Br. J. Psychiatry.: J. Ment. Sci. 190, 172-173.

Griffiths, K.M., Christensen, H., Jorm, A.F., 2008. Predictors of depression stigma. BMC
Psychiatry 8, 25

Griffiths, K.M., Crisp, D.A., Jorm, A.F., Christensen, H., 2011. Does stigma predict a belief in dealing with depression alone? J. Affect. Disord. 132, 413-417.

Griffiths, K.M., Christensen, H., Jorm, A.F., Evans, K., Groves, C., 2004. Effect of webbased depression literacy and cognitive-behavioural therapy interventions on stigmatising attitudes to depression: randomised controlled trial. Br. J. Psychiatry.: J. Ment. Sci. 185, 342-349.

Griffiths, K.M., Nakane, Y., Christensen, H., Yoshioka, K., Jorm, A.F., Nakane, H., 2006. Stigma in response to mental disorders: a comparison of Australia and Japan. BMC Psychiatry 6, 21.

Harris, F.M., Maxwell, M., O'Connor, R., Coyne, J.C., Arensman, E., Coffey, C., Koburger, N., Gusmao, R., Costa, S., Szekely, A., Cserhati, Z., McDaid, D., van Audenhove, C., Hegerl, U., 2016. Exploring synergistic interactions and catalysts in complex interventions: longitudinal, mixed methods case studies of an optimised multi-level suicide prevention intervention in four european countries (Ospi-Europe). BMC Public Health 16, 268.

Harris, F.M., Maxwell, M., O'Connor, R.C., Coyne, J., Arensman, E., Székely, A., Gusmão, R., Coffey, C., Costa, S., Cserháti, Z., Koburger, N., van Audenhove, C., McDaid, D., Maloney, J., Värnik, P., Hegerl, U., 2013. Developing social capital in implementing a complex intervention: a process evaluation of the early implementation of a suicide prevention intervention in four European countries. BMC Public Health 13, 158.

Hegerl, U., Kohls, E., 2016. Synergistic effects of multi-level suicide preventive interventions: important, but difficult to disentangle. Aust. N.Z. J. Psychiatry 50, $178-179$.

Hegerl, U., Althaus, D., Stefanek, J., 2003. Public attitudes towards treatment of depression: effects of an information campaign. Pharmacopsychiatry 36, 288-291.

Hegerl, U., Rummel-Kluge, C., Värnik, A., Arensman, E., Koburger, N., 2013. Alliances against depression - A community based approach to target depression and to prevent suicidal behaviour. Neurosci. Biobehav. Rev. 37, 2404-2409.

Hegerl, U., Wittenburg, L., Arensman, E., van Audenhove, C., Coyne, J.C., McDaid, D., van der Feltz-Cornelis, Christina, M., Gusmão, R., Kopp, M., Maxwell, M., Meise, U., Roskar, S., Sarchiapone, M., Schmidtke, A., Värnik, A., Bramesfeld, A., 2009. Optimizing suicide prevention programs and their implementation in Europe (OSPI Europe): an evidence-based multi-level approach. BMC Public Health 9, 428.

Jorm, A.F., Christensen, H., Griffiths, K.M., 2005. The impact of beyondblue. The national depression initiative on the Australian public's recognition of depression and beliefs about treatments. Aust. NZ J. Psychiatry 39, 248-254.

Koburger, N., Mergl, R., Rummel-Kluge, C., Ibelshauser, A., Meise, U., Postuvan, V., Roskar, S., Szekely, A., Ditta Toth, M., van der Feltz-Cornelis, C., Hegerl, U., 2015. Celebrity suicide on the railway network: can one case trigger international effects? J. Affect. Disord. 185, 38-46.

Kohn, R., Saxena, S., Levav, I., Saraceno, B., 2004. The treatment gap in mental health care. Bull. World Health Organ. 82, 858-866.

Makowski, A.C., Mnich, E.E., Ludwig, J., Daubmann, A., Bock, T., Lambert, M., Härter, M., Dirmaier, J., Tlach, L., Liebherz, S., dem Knesebeck, O. von, 2016a. Changes in beliefs and attitudes toward people with depression and schizophrenia - results of a public campaign in Germany. Psychiatry Res.

Makowski, A.C., Mnich, E.E., Ludwig, J., Daubmann, A., Bock, T., Lambert, M., Härter, M., Dirmaier, J., Tlach, L., Liebherz, S., dem Knesebeck, O, von, 2016b. Changes in beliefs and attitudes toward people with depression and schizophrenia - results of a public campaign in Germany. Psychiatry Res.

NICE, 2009. Depression in adults: recognition and management, London.

Paykel, E.S., Tylee, A., Wright, A., Priest, R.G., Rix, S., Hart, D., 1997. The defeat depression Campaign: psychiatry in the public arena. Am. J. Psychiatry 154, 59-65.

Rosen, A., Walter, G., Casey, D., Hocking, B., 2000. Combating psychiatric stigma. An overview of contemporary initiatives. Australas. Psychiat 8, 19-26.

Schomerus, G., Stolzenburg, S., Angermeyer, M.C., 2015. Impact of the Germanwings plane crash on mental illness stigma. Results from two population surveys in Germany before and after the incident. World Psychiatry 14, 362-363.

Thomson, W., 2011. Lifting the shroud on depression and premature mortality. A 49-year follow-up study. J. Affect. Disord. 130, 60-65.

Ustün, T.B., Ayuso-Mateos, J.L., Chatterji, S., Mathers, C., Murray, C.J.L., 2004. Global burden of depressive disorders in the year 2000. Br. J. Psychiatry.: J. Ment. Sci. 184, 386-392.

Wang, J., Lai, D., 2008. The relationship between mental health literacy, personal contacts and personal stigma against depression. J. Affect. Disord. 110, 191-196.

WMA, 2000. World Medical Association Declaration of Helsinki: ethical principles for medical research involving human subjects.

World Health Organization (WHO), 2012. Public Health Action For The Prevention Of Suicide. A framework. World Health Organization, Geneva, Switzerland (1 online resource)(22)

World Health Organization (WHO), 2014. Preventing Suicide. A global imperative. World Health Organization, Geneva, Switzerland, pp. 89 (eng).

Wright, A., McGorry, P.D., Harris, M.G., Jorm, A.F., Pennell, K., 2006. Development and evaluation of a youth mental health community awareness campaign - The Compass Strategy. BMC Public Health 6, 215. 